\title{
SIMULTANEOUS DETECTION OF VACCINAL AND FIELD INFECTIOUS BURSAL DISEASE VIRUSES IN LAYER CHICKENS CHALLENGED WITH A VERY VIRULENT STRAIN AFTER VACCINATION
}

\author{
Ivan DobrosavlJević ${ }^{1}$, Dejan Vidanović ${ }^{2}$, Maja VelHner ${ }^{3 *}$, Biljana MilJKoviĆ $^{4}$ \\ and Branislav LAKO ${ }^{5}$ \\ ${ }^{1}$ Veterinary Institute Požarevac, Požarevac, Serbia; ${ }^{2}$ Veterinary Institute Kraljevo, \\ Kraljevo, Serbia; ${ }^{3}$ Scientific Veterinary Institute 'Novi Sad', Rumenački put 20, \\ Novi Sad, Serbia; ${ }^{4}$ ResearchVeterinary Institute of Serbia, Belgrade, Serbia; \\ ${ }^{5}$ Faculty of Agriculture, Department for Veterinary Medicine Novi Sad, \\ University of Novi Sad, Novi Sad, Serbia
}

(Received 6 March 2013; accepted 2 July 2013)

\begin{abstract}
Infectious bursal disease virus is an important poultry pathogen. It is distributed worldwide and causes significant economic losses. In this study, a system was adopted for the simultaneous monitoring of vaccine and virulent strains using reverse transcription polymerase chain reaction (RT-PCR). After the decay of maternal antibodies, chickens were vaccinated at the age of 37 days with a virus of intermediate virulence and challenged at 5, 10 and 14 days post vaccination (dpv). The challenge was done with IBDV strain $\mathrm{CH} / 99$. Sequencing of the hypervariable region of VP2 has shown that $\mathrm{CH} / 99$ belongs to the very virulent group of viruses. The vaccine virus could be found in the bursa of Fabricius, spleen, thymus and bone marrow until $24 \mathrm{dpv}$. The $\mathrm{CH} / 99$ challenge virus was found in the bursa and lymphoid organs when chickens were challenged at 5 and $10 \mathrm{dpv}$. When challenge was performed at $14 \mathrm{dpv}$, the pathogenic virus could not be found in the bursa and other lymphoid organs.
\end{abstract}

Key words: Chicken, infectious bursal disease virus, PCR

Infectious bursal disease virus (IBDV) causes disease in young chickens by depletion of lymphocytes in the bursa of Fabricius and other lymphoid organs. IBDV belongs to the Birnaviridae family since the genome consists of double-stranded bisegmented RNA. The larger segment A encodes the viral polyprotein that is autocatalytically cleaved to produce viral proteins VP2, VP4 and VP3. A small open reading frame (ORF) partially overlapping the larger ORF encodes the VP5 protein. Genome segment B encodes the RNA-dependent RNA polymerase protein designated VP1 (Mundt et al., 1995). Mutations in the

*Corresponding author; E-mail: maja@niv.ns.ac.rs; Phone: 00381 (21) 489-5393; Fax: 00381 (21) 518-544 
hypervariable domain of VP2 can affect virulence and dominantly determine the antigenic nature of the virus (Azad et al., 1987; Rudd et al., 2002). IBDVs belonging to serotype 1 are infectious for chickens and, based on their pathogenicity, are further divided to attenuated, classic virulent and very virulent strains. On the American continent, antigenic variant viruses are present on poultry farms. These viruses do not cause an inflammatory reaction in the bursa during infection but severe atrophy of the bursa and immune suppression are observed. Serotype 2 viruses found in turkeys are not pathogenic for chickens or turkeys (Lasher and Shane, 1994).

Vaccination and good farm management are the only way to cope with the disease caused by IBDV. Since the beginning of the 1990s the very virulent viruses (vvIBDV) appeared in most countries of the world and this has made vaccination efforts more difficult. Namely, the vvIBDV can break through the maternal antibodies and infect young chickens before the live vaccine viruses have time to produce active immunity (Lasher and Shane, 1994). It has been reported that the presence of maternal antibodies causes a delay in the induction of antibodies by live attenuated vaccines and this creates an 'open window' for the infection with vvIBDV to occur (Rautenschlein et al., 2005; Zorman-Rojs et al., 2011). We postulated that on contaminated farms, pathogenic virus can co-exist with the vaccine strains, for a certain period of time, even if clinical disease does not develop. As such, the virus could contaminate poultry houses and subsequently be transmitted to healthy chickens.

The purpose of this research was to establish a method for the simultaneous detection of vaccine and pathogenic vvIBDV in Serbia with specific primers used in RT-PCR assay. This shall provide an assay for the detection of both viruses during the course of an IBDV infection in the field. Moreover, we were interested in finding out whether the pathogenic virus multiplies in the presence of a vaccine strain infection and for how long it could be detected in immunised chickens.

\section{Materials and methods}

\section{Extraction of viral RNA and reverse transcription polymerase chain reaction $(R T-P C R)$}

Viral RNA was extracted using the QIAamp viral RNA mini kit (Qiagen, Hilden, Germany). The samples of RNA were stored at $-80{ }^{\circ} \mathrm{C}$ until use. First the RT-PCR of the hypervariable region of VP2 in the CH/99 challenge strain was done. We used the primers that are recommended in the Sixth Edition of the Manual of Standards for Diagnostic Tests and Vaccines for Terrestrial Animals (OIE, 2008). The product length was 604 base pairs (bp). Specific primers described by Kusk et al. (2005) were applied for IBDV detection in the challenge experiment. The sequences of the primers are given in Table 1. Briefly, the prim- 
ers Vv-fp775 and Vv-rp1028 were designed to amplify a DNA fragment encompassing Alanine at 222 to Isoleucine at 294 of a vvIBDV strain. Another set of primers F52/D78/fp776 and D78/rp955 was specific for D78 vaccine virus and was designed for amplification of a gene fragment coding from Proline at 222 to Threonine at 270. The SuperScript III Platinum Quantitative One step RT/PCR System (Invitrogen, Carlsbad, California, USA) in single tube reaction was used. The reaction volume was $25 \mu$ l. Reverse transcription was done using the following conditions: denaturation $95{ }^{\circ} \mathrm{C} / 2 \mathrm{~min}$ and reverse transcription $55^{\circ} \mathrm{C} / 30 \mathrm{~min}$, enzyme inactivation $95^{\circ} \mathrm{C} / 5 \mathrm{~min}$, cooling at $4{ }^{\circ} \mathrm{C}$. The polymerase chain reaction was performed as follows: initialization $94{ }^{\circ} \mathrm{C} / 2 \mathrm{~min}$ and 37 cycles of denaturation $94{ }^{\circ} \mathrm{C} / 15 \mathrm{~s}$, annealing $62{ }^{\circ} \mathrm{C} / 30 \mathrm{~s}$, extension $72{ }^{\circ} \mathrm{C} / 30 \mathrm{~s}$, final elongation $72{ }^{\circ} \mathrm{C} / 5 \mathrm{~min}$.

The products were visualised in $2 \%$ agarose using gel electrophoresis (ultrapure agarose, Invitrogen, Carlsbad, California, USA) in TBE buffer with ethidium bromide. A 100-bp DNA marker was used (Fermentas, Lithuania). The length of amplicons was $143 \mathrm{bp}$ for the vaccine virus, while the product size for the virulent virus was $215 \mathrm{bp}$.

\section{Table 1}

Description of oligonucleotide primers used for amplification and sequencing of IBDV RNA

\begin{tabular}{llcc}
\hline Primer & \multicolumn{1}{c}{ Sequence (5'-3') } & Location $^{\mathrm{a}}$ & Polarity $^{\mathrm{b}}$ \\
\hline Vv-fp775 & AATTCTCATCACAGTACCAAG & $775-795$ & + \\
Vv-rp1028 & GCTGGTTGGAATCACAAT & $1011-1028$ & - \\
F52/D78-fp776 & ATTCTCATCACAGTACCAAC & $776-795$ & + \\
D78-rp955 & GCCCTGGTGATTACCGT & $939-955$ & - \\
\hline
\end{tabular}

${ }^{a}$ Nucleotide location numbered according to the F52/70 complete sequence (GenBank accession number D00869); ${ }^{b}$ Sense $(+)$ or antisense $(-)$ primers

\section{Sequencing of the PCR products}

The PCR products for the $\mathrm{CH} / 99$ virus were sequenced to determine whether the virulence markers for vvIBDV were present in this strain. The PCR product was purified using the QIAquick gel extraction kit (Qiagen, Hilden, Germany) according to the manufacturer's instructions. Quantification of DNA was done with the GeneRuler molecular standard (Fermentas, Lithuania). Sequencing was done according to the Sanger method with BigDye Terminator v3.1 kit (Applied Biosystems, USA). The alignment was done with the ClustalW programme. For the sequence comparison, the vvIBDV UK661 sequence was obtained from the GenBank (accession number X92760). 


\section{Viruses and preparation of challenge virus stock}

The vaccine strain D78 was used to immunise chickens in this experiment. The very virulent strain $\mathrm{CH} / 99$ was initially isolated from commercial pullets around 4 weeks of age that had previously been vaccinated on three occasions with a vaccine of intermediate virulence. The mortality in the flock was $20 \%$ (unpublished data). For this experiment, the $\mathrm{CH} / 99$ virus was used to challenge 6 broilers and subsequently 22 layer chickens free of antibodies to IBDV. The chickens were challenged with $0.1 \mathrm{ml}$ of the diluted virus into the eyes and nostrils. The mortality rate was $33 \%$ in broilers and $27 \%$ in layers. The chickens that survived were sacrificed at 4 days post infection (dpi) according to the provisions of Directive 86/609/EEC. Bursae were collected and homogenates were prepared in PBS at the ratio of 1:10. The supernatant from the bursa homogenates was stored at $-80{ }^{\circ} \mathrm{C}$ until use.

\section{Experimental design}

Day-old layer chickens were divided into three experimental groups marked $\mathrm{O} 1, \mathrm{O} 2$ and $\mathrm{O} 3$ and two control groups designated $\mathrm{K} 0$ and $\mathrm{K} 1$. Group K0 was neither vaccinated nor challenged and was used as a negative control. Group $\mathrm{K} 1$ was vaccinated but not challenged. Groups O1-O3 were vaccinated and challenged at different ages. In each group there were 30 chickens. The chickens were held in isolation rooms with feed and water ad libitum. At 35 days of age, blood samples were taken from 5 chickens per group. Antibodies were not found and subsequently the chickens were vaccinated and then challenged. At 37 days of age, Groups K1, O1, O2 and O3 were vaccinated with one dose of the commercial vaccine of intermediate virulence (D78 vaccine strain) by the oral route. At 5, 10 and 14 days post vaccination (dpv) blood samples were taken from chickens in groups $\mathrm{O} 1, \mathrm{O} 2$ and $\mathrm{O} 3$, respectively, and the chickens were subsequently challenged with the highly pathogenic IBDV (strain $\mathrm{CH} / 99$ ). The challenge was done orally with the prepared bursa homogenate diluted 1:10 in PBS. At 3, 7 and 10 dpi 3 chickens per group were sacrificed and the bursa, thymus, spleen and bone marrow were collected for RT-PCR analysis.

\section{Serology}

Serology testing was done by the use of a commercial ELISA kit (IDEXX Laboratories, Maine, USA) according to the manufacturer's instructions. The cut-off value was the titre of 396 .

\section{Results}

The hypervariable region of the VP2 gene of virus $\mathrm{CH} / 99$ was sequenced. The sequence includes nucleotides corresponding to 657-676 and 1193-1212 bp, 
coding for key amino acids essential for analysing the pathogenic nature of IBDV. The critical amino acids included Alanine (Ala) at 222, 284, Isoleucine (Ile) at 242, 256, 294, Glutamine (Gln) at 253 and Serine (Ser) at 299 (data not shown). The sequence alignments showed $99.07 \%$ nucleotide and $100 \%$ amino acid identity with the UK661 virus strain (Rudd et al., 2002), confirming that $\mathrm{CH} / 99$ belongs to the group of very virulent IBDVs. The sequence of $\mathrm{CH} / 99$ was submitted to the GenBank and was assigned the accession number KF439863.

In vaccinated and challenged birds, mortality and morbidity were not observed during the experiment. In the bursa and non-bursal organs of the control group (K0), neither the vaccine nor the pathogenic virus was detected using RTPCR. In Group K1, vaccine virus was detected in organs throughout the experiment, i.e. at 5, 10 and $14 \mathrm{dpv}$ (data not shown). The vaccine virus was also detected in all bursa samples during the experiment in Groups $\mathrm{O} 1, \mathrm{O} 2$ and $\mathrm{O} 3$, and it could be detected in the spleen and the thymus. In the bone marrow it was absent in Group O3 (chickens infected at $14 \mathrm{dpv}$ ), except in one sample at $7 \mathrm{dpi}$. The virulent virus $\mathrm{CH} / 99$ was found in the bursa and other lymphoid organs in Groups $\mathrm{O} 1$ and $\mathrm{O} 2$ (5 and $10 \mathrm{dpv}$ ) throughout the experiment. If the infection was done at $14 \mathrm{dpv}$ (Group O3), the RT-PCR for challenge virus was negative in the bursa, spleen, thymus and bone marrow (Fig. 1).

The results of serology are presented in Fig. 2. At 35 days of age, antibody ELISA test was negative in all groups. At $5 \mathrm{dpv}$, IBDV antibodies were also not found in the chickens tested (Groups K1 and O1). Ten days post vaccination, low antibody titre was found in the vaccinated birds (Groups K1 and O2). As expected, at $14 \mathrm{dpv}$ the antibody titre was increased, showing further development of humoral response to vaccination (Fig. 2).

\section{Discussion}

In this study, the $\mathrm{CH} / 99$ virus was sequenced to determine its genetic relationship to vvIBDV strains. Molecular data on the hypervariable domain of VP2 for IBDV isolated in Southeastern Europe were reported by Zorman-Rojs et al. (2003). The sequences obtained in their research showed a high percentage of identity with the vvIBDV strain UK661 (Zorman-Rojs et al., 2003). A similar result was obtained with the $\mathrm{CH} / 99$ virus. Because village chickens are not vaccinated regularly, backyard chicken flocks present a reservoir for the virus in Serbia. Multi-age farming in broiler and some layer farms is occasionally practised in Serbia. Since older birds increase the risk of vvIBDV transmission to younger birds, we wanted to check whether it is possible to detect very virulent virus in vaccinated chickens. We attempted to introduce a system for the selective detection of both viruses (i.e. D78 vaccine and very virulent viruses) with the RT-PCR method. The vaccine virus was found in the bursa as long as $14 \mathrm{dpv}$. The results 

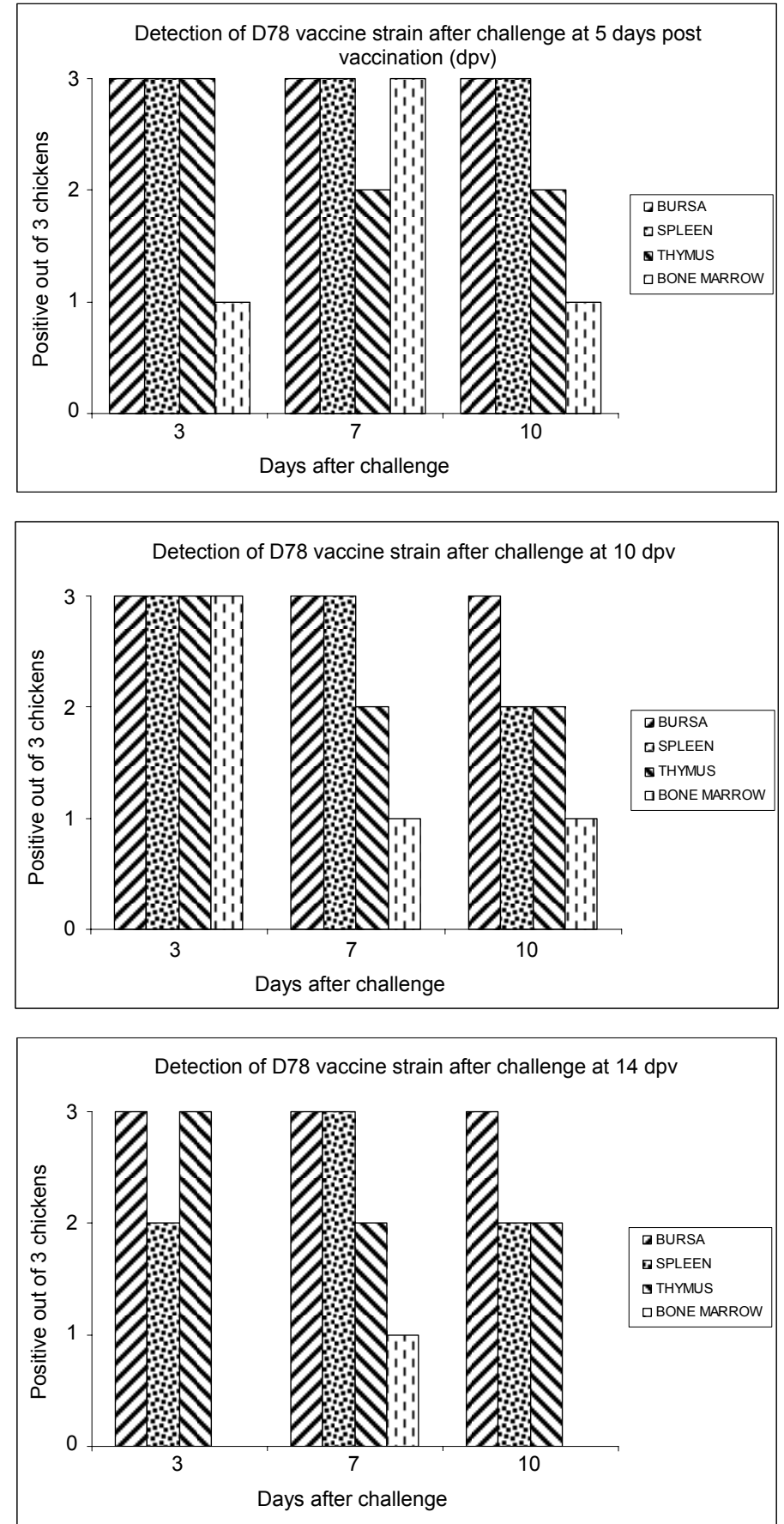

Fig. 1. Detection of the RT-PCR products for vaccine virus (D78) and vvIBDV $(\mathrm{CH} / 99)$ during the experiment 

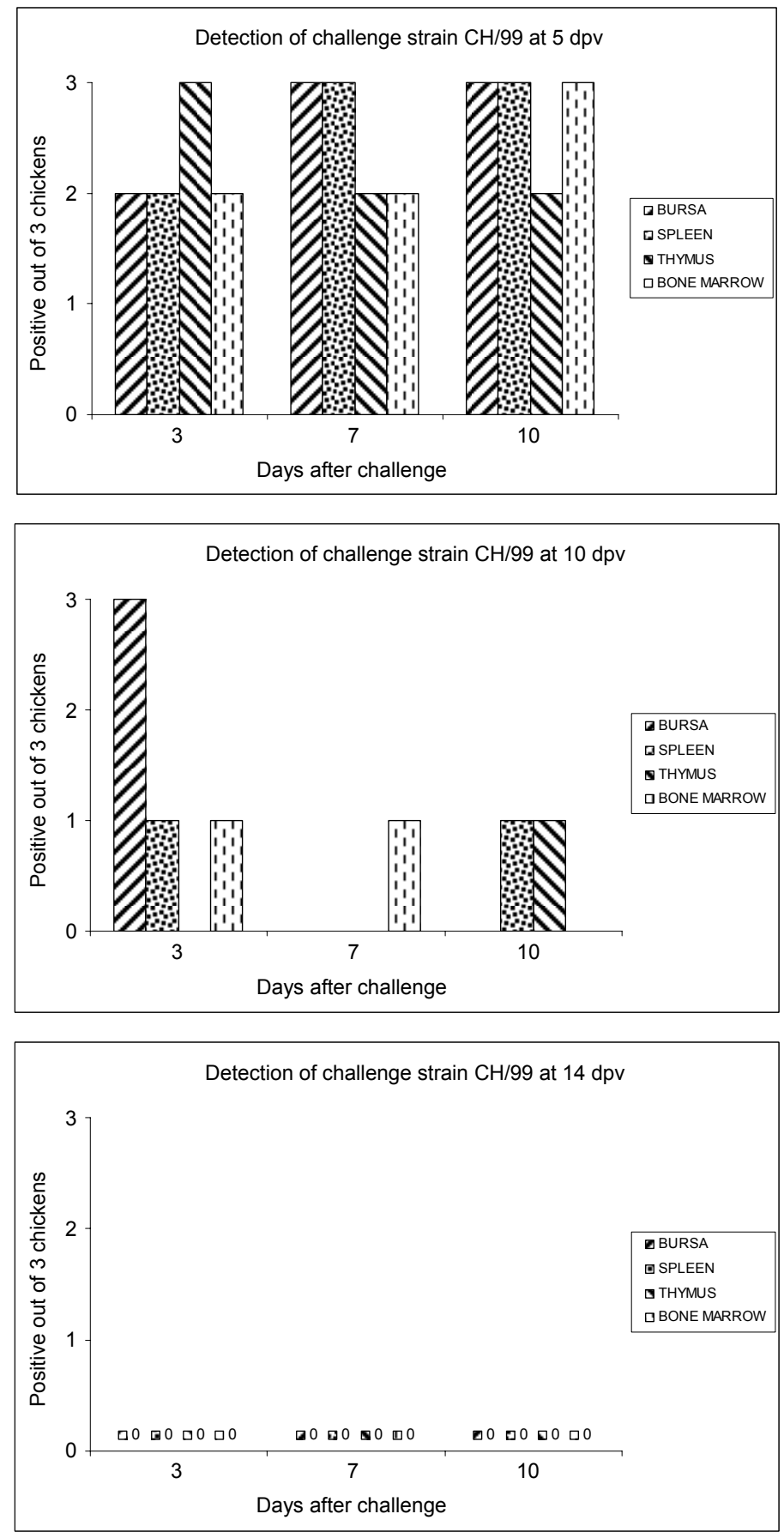

Fig. 1 (Continued) 


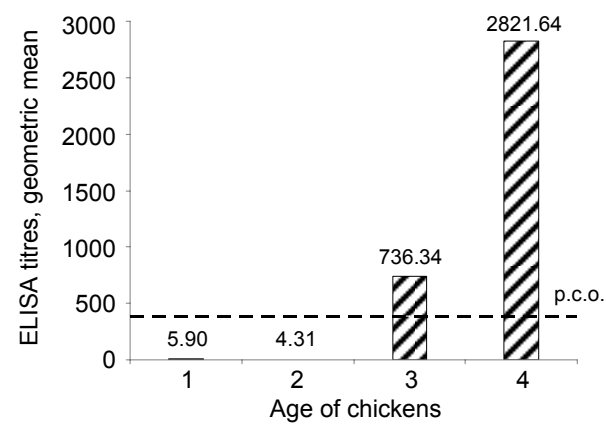

Fig. 2. ELISA antibody titres: 1 - at 35 days of age, ELISA titres before vaccination at 37 days of age; 2 - at 42 days of age, on the day of challenge, Group O1; 3 - at 47 days of age, on the day of challenge, Group O2; 4 - at 51 days of age, on the day of challenge, Group O3

obtained are similar to those found in the experiments of Rautenschlein et al. (2005) who detected vaccine virus of intermediate virulence at $14 \mathrm{dpv}$ by immunohistochemical staining, while the intermediate plus vaccine strain was detectable as long as $21 \mathrm{dpv}$. In this experiment the vaccine virus was also found in the spleen, thymus and bone marrow. It is interesting to note that, in one bone marrow sample, the vaccine strain of IBDV was present even at $21 \mathrm{dpv}$. Kabell et al. (2005) detected vaccine virus in the bursa only. Combining the RT-PCR test and ELISA, Barlič-Maganja et al. (2002) succeeded in detecting the vaccine virus in the spleen, thymus and caecal tonsils for prolonged periods of time. In this respect, our results are in good correlation with theirs. Tanimura et al. (1995) found the J1 strain (mild virus) in caecal tonsils and thymus at 7 dpi using immunohistochemical staining. Tsukamoto et al. (1995) used an antigen capture ELISA test to detect mild and very virulent viruses in the lymphoid organs of infected SPF chickens. The mild strains could not be found in the thymus, spleen and bone marrow after 3 dpi. Differences in the results of detection of the vaccine virus in various experiments are possibly due to the age of chickens at the time of infection, the breed and the various laboratory methods used in the studies. It was previously discovered that very virulent viruses multiply to higher titres in non-bursal organs, compared to moderately virulent strains (Tanimura et al., 1995). The very virulent strain Ehime/91 was found at 7 dpi only in the bursa and spleen in the experiment of Tsukamoto et al. (1995). In the experiment presented here the challenge virus was detected in almost all bursae and non-bursal organs when infection took place at 5 $\mathrm{dpv}$ (Group O1). If infection was done at $10 \mathrm{dpv}$ (Group O2), the $\mathrm{CH} / 99$ virus was present in all bursae at $3 \mathrm{dpi}$ and could be detected in one bird each from spleen, bone marrow or thymus at different time points after challenge. The $\mathrm{CH} / 99$ virus was completely absent when challenge was done at $14 \mathrm{dpv}$. It was previously postulated that the vaccine and virulent viruses diminish due to clearance of the virus by the antibodies (Iván et al., 2005). This assumption could explain the disappearance of the vvIBDV in some lymphoid organs in birds infected at $10 \mathrm{dpv}$ in this 
experiment (Fig. 1). The long presence of the vaccine virus is perhaps due to other mechanisms. It could be postulated that if the vaccine virus infects bursal cells before the virulent strain, it develops an advantage, most likely enhancing specific cellular/immunological processes and functions. In the research of Jackwood (2011), chickens with maternal antibodies were infected with vvIBDV at different time points. It was concluded that maternally derived antibodies have strong protective effect, but did not prevent replication of the vvIBDV even though at 2 weeks of age the antibody titre was high. The author also reported that variant viruses prevented replication of vvIBDV if inoculated into the chickens 10 days before vvIBDV and $48 \mathrm{~h}$ before vvIBDV. When vvIBDV was given simultaneously with the variants, the clinical signs characteristic of very virulent viruses occurred and the bursal lesions resembled those typical of vvIBDV infection. High levels of maternal antibodies but also the persistent infection with variant viruses may explain the relative absence of vvIBDV in the USA. In our experiment, antibody titres induced with the vaccine virus well correlated with detection of the challenge virus in the bursa. When the challenge was performed in face of high antibody level at $14 \mathrm{dpv}$, both the clinical signs and the replication of vvIBDV were prevented. When antibodies were absent at $5 \mathrm{dpv}$, the vvIBDV was present in the bursa and other lymphoid organs, but the disease did not develop, in the same way as observed in the experiments of Jackwood (2011). The humoral immune response has a major role in protection against IBDV. However, there is evidence that cell-mediated immunity also plays an important part in the protection against early virus infection. This is supported by finding an influx of T cells in the bursa (Tanimura and Sharma, 1997). It was also shown that $\mathrm{T}$ cells become activated during IBDV infection (Kim et al., 2000), that cytokines IL-2 and IFN $\gamma$ are released during the early stage of the infection (Rautenschlein et al., 2002) and that in bursectomised chickens $\mathrm{T}$ cells are responsible for virus clearance (Yeh et al., 2002). Since at $5 \mathrm{dpv}$ clinical protection against IBDV occurs in infected chickens, it could be postulated that a cell-mediated immune response may have prevented strong replication of the vvIBDV strain $\mathrm{CH} / 99$.

From the present research we conclude that in vaccinated flocks receiving an intermediate vaccine the very virulent virus can produce subclinical infection for a limited period only. The possibility of spreading the very virulent virus among vaccinated flocks presents an additional risk for farmers that practise multi-age farm management. Careful monitoring of IBDV epidemiology is important and needs to be backed up with sensitive laboratory diagnostic methods.

\section{Acknowledgements}

We wish to thank Professor Daral Jackwood for critical reading of the manuscript. This work was supported by a grant from the Ministry of Education Science and Technological Development, Republic of Serbia, Project Number TR 31071. 


\section{References}

Azad, A. A., Jagadish, M. N., Brown, M. A. and Hudson, P. J. (1987): Deletion mapping and expression in Escherichia coli of the large genomic segment of birnavirus. Virology 161, 145-152.

Barlič-Maganja, D., Zorman-Rojs, O. and Grom, J. (2002): Detection of infectious bursal disease virus in different lymphoid organs by single-step reverse transcription polymerase chain reaction and microplate hybridization assay. J. Vet. Diagn. Invest. 14, 243-246.

Iván, J., Velhner, M., Ursu, K., Germán, P., Mató, T., Drén, C. N. and Mészáros, J. (2005): Delayed vaccine virus replication in chickens vaccinated subcutaneously with immune complex infectious bursal disease vaccine: Quantification of vaccine virus by real-time polymerase chain reaction. Can. J. Vet. Res. 69, 135-142.

Jackwood, D. J. (2011): Viral competition and maternal immunity influence the clinical disease caused by very virulent infectious bursal disease virus. Avian Dis. 55, 398-406.

Kabell, S., Handberg, K. J., Kusk, M. and Bisgaard, M. (2005): Detection of infectious bursal disease virus in various lymphoid tissue of experimentally infected specific pathogen free chickens by different reverse transcription polymerase chain reaction assays. Avian Dis. 49, 534-539.

Kim, I. J., You, S. K., Kim, H., Yeh, H. Y. and Sharma, J. M. (2000): Characteristics of bursal T lymphocytes induced by infectious bursal disease virus. J. Virol. 74, 8884-8892.

Kusk, M., Kabell, S., Jørgensen, P. H. and Handberg, K. J. (2005): Differentiation of five strains of infectious bursal disease virus: Development of a strain-specific multiplex PCR. Vet. Microbiol. 109, 159-167.

Lasher, H. N. and Shane, S. M. (1994): Infectious bursal disease. World Poult. Sci. J. 50, 133-166.

Mundt, E., Beyer, J. and Müller, H. (1995): Identification of a novel viral protein in infectious bursal disease virus-infected cells. J. Gen. Virol. 76, 437-443.

OIE (2008): OIE Manual of Diagnostic Tests and Vaccines for Terrestrial Animals. Sixth Edition. Paris, 2008. pp. 549-565.

Rautenschlein, S., Kraemer, Ch., Vanmarcke, J. and Montiel, E. (2005): Protective efficacy of intermediate and intermediate plus infectious bursal disease virus (IBDV) vaccines against very virulent IBDV in commercial broilers. Avian Dis. 49, 231-237.

Rautenschlein, S., Yeh, H. Y., Njenga, M. K. and Sharma, J. M. (2002): Role of intrabursal T cells in infectious bursal disease virus (IBDV) infection: $\mathrm{T}$ cells promote viral clearance but delay follicular recovery. Arch. Virol. 147, 285-304.

Rudd, M. F., Heine, H. G., Sapats, S. I., Parede, L. and Ignjatović, J. (2002): Characterization of an Indonesian very virulent strain of infectious bursal disease virus. Arch. Virol. 147, 1303-1322.

Tanimura, N. and Sharma, J. M. (1997): Appearance of T cells in the bursa of Fabricius and cecal tonsils during the acute phase of infectious bursal disease virus infection in chickens. Avian Dis. 41, 638-645.

Tanimura, N., Tsukamoto, K., Nakamura, K., Narita, M. and Maeda, M. (1995): Association between pathogenicity of infectious bursal disease virus and viral antigen distribution detected by immunohistochemistry. Avian Dis. 39, 9-20.

Tsukamoto, K., Tanimura, N., Mase, M. and Imai, K. (1995): Comparison of virus replication efficiency in lymphoid tissue among three infectious bursal disease virus strains. Avian Dis. 39, 844-852.

Yeh, H. Y., Rautenschlein, S. and Sharma, J. M. (2002): Protective immunity against infectious bursal disease virus in chickens in the absence of virus-specific antibodies. Vet. Immunol. Immunopathol. 89, 149-158.

Zorman-Rojs, O., Barlič-Maganja, D., Mitevski, D., Lübke, W. and Mundt, E. (2003): Very virulent infectious bursal disease virus in Southeastern Europe. Avian Dis. 47, 186-192.

Zorman-Rojs, O., Krapež, U., Slavec, B., Juršić-Cizerl, R. and Poljanec, T. (2011): Field efficacy of different vaccines against infectious bursal disease in broiler flocks. Acta Vet. Hung. 59, $385-398$. 